\title{
The Effect of Datura Innoxia Seeds and Leaves Contents on Albino Wister Rats
}

Ali A Eltayeib ${ }^{1 *}$, Siddigen ANT Matter ${ }^{2}$

\author{
${ }^{1,2}$ Department of Chemistry, Faculty of Science, Kordofan \\ University, Sudan
}

\author{
"Correspondence author \\ Ali A Eltayeib \\ Department of Chemistry \\ Faculty of Science \\ Kordofan University \\ Sudan
}

Submitted : 31 Aug 2020 ; Published : 23 Sept 2020

\begin{abstract}
The aim of the study was to evaluate the toxic effect of Datura innoxia seeds and leaves on experimental rats by determining the elements content of seeds and leaves, the chemical compounds in aqueous and methanolic extracts of seeds and leaves and the chemical compounds in the stomach content of rats. Seeds and leaves were collected from El-Obied, North Kordofan State, Sudan, in October, 2016. The aqueous and methanol extracts were carried out by using maceration method and soxhelt apparatus respectively. Sixty five male albino wister rats, three months old and with an average body weight ranged 110-120 g, were randomly divided into thirteen groups, consisting of five rats in each group. Group 1 served as control and fed with normal rats food and water for thirty days. Groups 2, 6 and 10 administered aqueous seeds extract, groups 4, 8 and 12 received methanol seeds extract, groups 3, 7 and 11 received aqueous leaves extracts, groups 5, 9 and 13 received methanol leaves extract, all the groups received the same type of extract were administered 40, 60 and $80 \mathrm{mg} /$ $\mathrm{kg}$ body weight respectively. The extracts administered to the rats intra gastrically using cathodal tube daily for thirty days. The elements in the leaves and seeds ( $\mathrm{K}, \mathrm{Ca}, \mathrm{S}, \mathrm{Si}, \mathrm{Cl}, \mathrm{Fe}, \mathrm{Al}, \mathrm{P}, \mathrm{Mg}, \mathrm{Ti}, \mathrm{Mn}, \mathrm{Zn}, \mathrm{Sr}, \mathrm{Cu}, \mathrm{V}, \mathrm{Br}$ and $\mathrm{Zr}$ ) were determined by energy-dispersive X-ray fluorescence (EDXRF) spectroscopy. K content was the highest in seeds (5.469 $\pm 0.021 \%), C a$ and $\mathrm{S}$ the highest in leaves $(2.461 \pm 0.019 \%, 1.254 \pm 0.022 \%$ respectively). The elements $\mathrm{Ti}, \mathrm{Mn}, \mathrm{Sr}, \mathrm{V}, \mathrm{Br}$ and $\mathrm{Zr}$ were detected in the leaves with range concentration 0.062-0.002\%. The elements $\mathrm{Si}, \mathrm{Cl}, \mathrm{Fe}, \mathrm{Al}, \mathrm{P}, \mathrm{Mg}$ and $\mathrm{Zn}$ concentration in seeds varied from 0.002 to $0.942 \%$ and in leaves varied from 0.014 to $0.346 \%$. The concentration of these elements did not exceed the standard dangerous toxic levels. The effects of oral administration of leaves and seeds extracts to 60 healthy rats over 30 days were evaluated by monitoring the chemical changes of stomach contents. The analysis by gas chromatography-mass spectrometry (GC-MS) of aqueous and methanolic extracts revealed the presence of alkaloids (scopolamine, atropine and hyoscyamine), fatty acids, esters, amides, amino acids, ketones, coummarins, terpinoids, phenols, alcohols and hydrocarbons compounds. New compounds appeared in the stomach contents in the treated groups and this suggest that some compounds were metabolized and circulated in the body after the oral administration of leaves and seeds extract. The study concluded that the toxicity of seeds and leaves (methanolic and aqueous) extracts are nearly have the same toxic effects on rats due to their same active ingredients (alkaloids) and the oral administration of the extracts was found to be safe up to $40 \mathrm{mg} / \mathrm{kg}$.
\end{abstract}

Keywords : Chemical Elements; Stomach Contents; Aqueous Extract; Methanolic Extract

\section{Introduction}

The applications of medicinal plants in most developing countries for the treatment of various diseases have been widely observed by Educational Scientific, United Nations and Cultural Organization (UNESCO, 1996) [1]. The medicinal properties of plants could be based on the antimicrobial, antioxidant and antipyretic effects of the secondary metabolite in them [2]. According to World Health Organization (WHO), medicinal plants would be the best source to obtain a variety of drugs [3]. The medicinal plants are widely used by all sections of community, whether directly as folk remedies or the medicaments of the different indigenous systems as well as in modern medicine system [4]. Datura species are herbaceous, leafy annuals and short-lived perennials which can reach up to $2 \mathrm{~m}$ in height, belongs to the classic "witches' weeds", along with deadly nightshade, henbane, and mandrake. Most parts of the plant are toxic, and have a long history of use for causing delirious states and death. It was well known as an essential ingredient of potions and witches brews [5]. Several 
species of datura have been used and are still extensively used in many parts of the world as healing and as hallucinogenic plants. The medicinal and hallucinogenic effects are caused by tropane alkaloids: atropine, hyoscyamine and scopolamine. These are fine and medicinal when taken in small doses but have very harmful effects when taken in large quantities causing delirium, loss of body control, cramps and eventual death. The accidental occurrence of seeds of D. stramonium found in sorghum flour from a mill in Moshupa village caused temporary memory losses to a number of people in the village in May 1998 [6]. Traditional medicine uses flowers, leaves and seed of $D$. innoxia medically treat for skin eruptions, colds, and nervous disorders [7]. It has been used in the past as an antispasmodic, hallucinogenic, hypnotic and narcotic and also in the treatment of insanity, impotence, asthma, diarrhea, as an analgesic, to control fever, kill parasites, and skin diseases [8].

\section{Materials and Methods}

\section{Plant material (seeds and leaves)}

D. innoxia seeds and leaves were collected from Elobied, North Kordofan state, Sudan in October, 2016. The plant was authenticated by a plant taxonomist at the Department of Botany Faculty of Science University of Kordofan to be Datura innoxia. The plant leaves and seeds were cleaned, shade-dried and grinded by a mechanical grinder.

\section{Animals (rats)}

Sixty five male wister rats, three months old and with an average body weight ranged (110-120g), were used in the present study. The rats were clinically healthy and housed within the premises of the Faculty of Science and Technology, Sudan University, Khartoum.

Animal housed under standard husbandry conditions $\left(30^{\circ} \mathrm{C} \pm\right.$ $2{ }^{\circ} \mathrm{C}, 60-70 \%$ relative humidity and 12 hour day-night cycle) and fed on the rat diet (flour $55.6 \%$, meat $35 \%$, edible oil $7.5 \%$, sodium chloride $1.2 \%$ and vitamins and minerals $0.7 \%$ ) and water provider. Animal experiments were designed and conducted in accordance with the guidelines of institutional animal ethical committee.

\section{Methods}

\section{Extraction by petroleum ether and methanol}

The extraction was carried out according to method described by Sukhdev et al., [9]. $600 \mathrm{~g}$ of each coarsely powdered sample (seeds and leaves) was successively extracted with $1200 \mathrm{ml}$ of petroleum ether and $1200 \mathrm{ml}$ of methanol using soxhlet extractor apparatus. Extraction was carried out for about four hours for petroleum ether and eight hours for methanol till the color of solvents at the last siphoning time returned colorless. Solvents were evaporated under reduced pressure using rotary evaporator apparatus. Finally the extracts allowed to air till complete dryness.

\section{Extraction by water}

For aqueous extract, $600 \mathrm{~g}$ of each coarsely powdered sample (seeds and leaves) was extracted with $3000 \mathrm{ml}$ of distilled water and heat to $70 \mathrm{oc}$ for three hours and filtered through what man paper No. 0.1 and dried further by freeze drier.

\section{Preparation of stock solutions}

The preparation of stock solution was done by dissolving $5 \mathrm{~g}$ of each extract in $12.5 \mathrm{ml}$ of $99.9 \%$ ethyl alcohol and completed to $250 \mathrm{ml}$ with distilled water and then $2 \mathrm{ml} ; 3 \mathrm{ml}$ and $4 \mathrm{ml} \mathrm{(40}$ $\mathrm{mg}, 60 \mathrm{mg}$ and $80 \mathrm{mg}$ ) were taken from the stock solution and used as doses for rats orally.

\section{Experimental Design}

A total of sixty five male wister albino rats divided into thirteen groups containing five each. Group 1served as control and fed with normal rat food and water for thirty days. Groups 2, 3 and 4 received methanol seeds extract with dose of 40,60, $80 \mathrm{mg} / \mathrm{kg}$ body weight/day respectively and Groups 5, 6 and 7 received methanol leaves extract with dose of 40,60 , and $80 \mathrm{mg} / \mathrm{kg}$ body weight /day respectively. Groups 8, 9 and 10 received aqueous seeds extract with dose of 40,60, $80 \mathrm{mg} /$ $\mathrm{kg}$ body weight/day respectively and Groups 11, 12 and 13 received aqueous leaves extract with dose of 40,60, and 80 $\mathrm{mg} / \mathrm{kg}$ body weight /day respectively. The extract administered to the rats intra gastrically using cathidel tube for thirty days. The method was prepared according to the Standard Method of Organization for Economic Cooperation and Development (OECD 425) [10]. The daily feed intake was monitored in the rats until termination of the experiment. On the day thirty stomach contents were collected for chemical compounds screening.

\section{Biological samples preparation for GC-MS analysis}

The refrigerated samples allowed equilibrating to room temperature for 5 minutes before extraction. The minimum volume of gastric content is $4 \mathrm{ml}$ [9].

\section{Preparation of stomach contents}

The samples were shaken well by hand for 3 minutes to homogenize. The whole sample placed into a beaker and mixed well with approximately equal volume of distilled water for 3 minutes using a vortex. After shaking the sample was allowed to stand for few minutes then two layers separated. $4 \mathrm{ml}$ of the upper layer were taken using a disposable plastic pipette and put into a separatory funnel.

\section{Preparation of stomach contents (acidic extract)}

The $\mathrm{pH}$ of the sample in the separatory funnel adjusted to 3 with $0.5 \mathrm{ml}$ of dilute $\mathrm{HCl}$. After the adjustment of the $\mathrm{pH}$ to $3,20 \mathrm{ml}$ of dichloromethane was added to the sample in the separatory funnel and the mixture was shaken for 3 minutes and after that two layers appeared. The lower layer (dichloromethane layer) was separated from the upper layer (aqueous layer) and filtered through a filter paper contain 10.0 gm of anhydrous sodium sulphate to absorb water.

\section{Preparation of stomach contents (basic extract)}

To the aqueous layer of stomach contents in the acidic extract $200 \mu \mathrm{l}$ of $25 \%$ ammonium hydroxide was added to adjust the 
$\mathrm{pH}$ of the sample to 10 , then $6 \mathrm{ml}$ of dichloromethane was added to the mixture in the separatory funnel and vortex for 10 sec. and then allowed to settle. After the settlement two layers appeared. The lower layer was separated from the upper layer and filtered through a filter paper contained $10 \mathrm{~g}$ of anhydrous sodium sulphate. The acidic and basic extracts were mixed; $3 \mathrm{ml}$ of the mixture was taken and poured in a test tube. The mixture in the test tube was dried by nitrogen gas dryer. $0.5 \mathrm{ml}$ of methanol was added to the dry mixture.

\section{GC-MS analysis conditions}

The chemical composition analysis of the samples were carried out by using GC/MS technique model -TQ8040 from Japan with capillary column (RTX-5MS), column oven temperature $800 \mathrm{C}$, injection temp. $2500 \mathrm{C}$, the sample was injected by using split mode, pressure $122 \mathrm{kpa}$, total flow $50 \mathrm{ml} / \mathrm{min}$, column flow $1.80 \mathrm{ml} / \mathrm{min}$, purge flow $6 \mathrm{ml} / \mathrm{min}$, split ratio -1 , helium as the carrier gas, ion source temp. $2000 \mathrm{C}$, interface temp. $2500 \mathrm{C}$, solvent cut time $2.5 \mathrm{~min}$, detector gain $+0.30 \mathrm{kv}$, threshold 1000 , start time $3 \mathrm{~min}$, end time $21.00 \mathrm{~min}$, acquisition Mode Q3Scan, start $\mathrm{m} / \mathrm{z} 25$, end $\mathrm{m} / \mathrm{z} 400$, the oven temp. program start from $800 \mathrm{C}$ with rate $150 \mathrm{C} / \mathrm{min}$ to $2000 \mathrm{C}$ with $1 \mathrm{~min}$ hold time to $2600 \mathrm{C}$ with rate $100 \mathrm{C} / \mathrm{min}$ with $1 \mathrm{~min}$ hold time to $2800 \mathrm{C}$ as final temp. with 2 min hold time.

\section{Results and Discussion}

The content of the elements $\mathrm{K}, \mathrm{Ca}, \mathrm{S}, \mathrm{Si}, \mathrm{Cl}, \mathrm{Fe}, \mathrm{Al}, \mathrm{P}, \mathrm{Mg}, \mathrm{Mn}$, $\mathrm{Ti}, \mathrm{Zn}, \mathrm{Sr}, \mathrm{Cu}, \mathrm{V}, \mathrm{Br}$ and $\mathrm{Zr}$ was determined in Datura innoxia seeds and leaves as shown in table 1 . Eleven elements namely $\mathrm{K}, \mathrm{Ca}, \mathrm{S}, \mathrm{Si}, \mathrm{Cl}, \mathrm{Fe}, \mathrm{Al}, \mathrm{P}, \mathrm{Mg}, \mathrm{Zn}$ and $\mathrm{Cu}$ were detected in varied concentration in Datura innoxia seeds and leaves while $\mathrm{Ti}, \mathrm{Mn}, \mathrm{Sr}, \mathrm{V}, \mathrm{Br}$ and $\mathrm{Zr}$ were not detected in seeds but detected in leaves. Table 1 showed that the Datura innoxia seeds contain high percent of $\mathrm{K}$ compared to other elements detected in the seeds meanwhile the leaves contain high percent of $\mathrm{Ca}$ and $\mathrm{S}$ compared to other elements detected in leaves. The elements $\mathrm{Ti}, \mathrm{Mn}, \mathrm{Sr}, \mathrm{V}$ and $\mathrm{Br}$ were found in low percentage in leaves (0.062, 0.035, 0.011, 0.005, 0.005 and $0.002 \%$ respectively). The elements $\mathrm{Ti}, \mathrm{Mn}, \mathrm{Sr}, \mathrm{V}, \mathrm{Br}$ and $\mathrm{Zr}$ were not detected in seeds. $\mathrm{Cu}$ and $\mathrm{Zn}$ were found in low percentage in both seeds and leaves. All the heavy metals concentrations found were under the internationally permitted limits, some of them are natural constituents of the environment and found in varying levels in the soil, ground and surface water. Some minerals are essential, required for normal metabolism of organisms and various physiological according to Martin and Coughtrey (1982) [11].

\begin{tabular}{|l|l|l|}
\hline Elements & Seeds & Leaves \\
\hline & $\%(\mathrm{~W} / \mathrm{W}) \pm \mathrm{SD}$ & $\%(\mathrm{~W} / \mathrm{W}) \pm \mathrm{SD}$ \\
\hline $\mathrm{K}$ & $5.469 \pm 0.021$ & $0.570 \pm 0.003$ \\
\hline $\mathrm{Ca}$ & $0.037 \pm 0.001$ & $2.461 \pm 0.019$ \\
\hline $\mathrm{S}$ & $0.037 \pm 0.002$ & $1.254 \pm 0.022$ \\
\hline $\mathrm{Si}$ & $0.942 \pm 0.015$ & $0.051 \pm 0.001$ \\
\hline $\mathrm{Cl}$ & $0.647 \pm 0.011$ & $0.078 \pm 0.002$ \\
\hline
\end{tabular}

\begin{tabular}{|l|l|l|}
\hline $\mathrm{Fe}$ & $0.008 \pm 0.000$ & $0.346 \pm 0.003$ \\
\hline $\mathrm{Al}$ & $0.012 \pm 0.005$ & $0.226 \pm 0.008$ \\
\hline $\mathrm{P}$ & $0.08 \pm 0.001$ & $0.080 \pm 0.007$ \\
\hline $\mathrm{Mg}$ & $0.012 \pm 0.007$ & $0.068 \pm 0.015$ \\
\hline $\mathrm{Ti}$ & $0.000 \pm 0.000$ & $0.062 \pm 0.003$ \\
\hline $\mathrm{Mn}$ & $0.000 \pm 0.000$ & $0.035 \pm 0.001$ \\
\hline $\mathrm{Zn}$ & $0.002 \pm 0.000$ & $0.014 \pm 0.000$ \\
\hline $\mathrm{Sr}$ & $0.000 \pm 0.000$ & $0.011 \pm 0.001$ \\
\hline $\mathrm{Cu}$ & $0.000 \pm 0.000$ & $0.008 \pm 0.001$ \\
\hline $\mathrm{V}$ & $0.000 \pm 0.000$ & $0.005 \pm 0.002$ \\
\hline $\mathrm{Br}$ & $0.000 \pm 0.000$ & $0.005 \pm 0.000$ \\
\hline $\mathrm{Zr}$ & $0.000 \pm 0.000$ & $0.002 \pm 0.001$ \\
\hline
\end{tabular}

Table 1: Contents of elements in Datura innoxia leaves and seeds analyzed by EDXRF technique.

\section{Chemical compounds of rats stomach contents (control group)}

The chemical compounds screening of stomach contents of the control group identified by GC-MS analysis revealed 21 compounds. These compounds are as follows: Coummarins (Furan,2,5-bis(3,4-dimethoxyphenl)tetrahydro-3,4-dimethyl,[2R-(2.alpha.,3-beta.,4-beta.,5-alpha.)\}, Scoparone (2H-1Benzopyran-2-one,6,7- dimethoxy), amides N,NDimethyl-N-phenyl formamidine, (N,N,-di-sec-butyl- pphenylene diamine, 3,3-Dimethyl-1-(2-carboxyphenyl) triazene, fatty acids and esters, (9-Oxononanoic acid, Butanoicacid,3-hydroxy-3-methyl-,(Ibuprofen), (Benzene acetic acid, alpha,-methyl-4-(2-methylpropyl), Acetic acid, Benzoic acid,3-methyl, phenyl-, isopentyl ester, Pentanoic acid, pentyl ester, Benzenz acetic acid,4-(1,1-dimethylethyl),methyl ester, Pentanoic acid,1-methyl ester, Phenyl acetic acid propyl ester, Benzene acetic acid ethyl ester, Pentanoic acid, propyl ester. Phenolic compounds such as: Pentyl phenylacetate, phenols (Phenol,2,2,- methylenebis $\{6-(1,1-$ dimethylethyl)-4-ethyl, Phenyl,2,1-(1,1- dimethylethyl), Phenol,3-methyl-5-(1-methylethyl)-,methylcarbamate, Alpha Isomethyl ionone, Cyclohexane,2-ethenyl-1,3,3-trimethyl, and heterocyclic aromatic compounds (Pyridine,3-(1-methyl-2pyrrolidinyl)-, Pyrrolidine,1-(2- chloroethyl)-, and monomers (3-(3-Pyridyl)acrylic acid).

Chemical compounds of rats stomach contents supplemented with $40 \mathrm{mg} / \mathrm{kg}$ methanol extract of seeds The analysis by GC-MS showed the presence of 20 compounds. These compounds are as follows: Alkaloids (scopolamine, atropine, tropine, tropinone, 3-tropanone, pseudoecgonine methyl ester, apoatropin, hyoscyamine, tropacocaine, tiglypseudotropin, homatropine, azerdine, 1-methyl and 8 -azabi cyclo $\{3,2,1\}$ octane-3,6-diol,acetate (ester)) and fatty acids (tropic acid, oleic acid, palmatic acid, azelaic acid and linoleic ethyl ester). 
Chemical compounds of rats stomach contents treated with $40 \mathrm{mg} / \mathrm{kg}$ of methanol extract of leaves

The GC-MS analysis revealed 49 compounds. These compounds are as follows: Alkaloid compounds (scopolamine, atropine, tropine, tropinone, 3-tropanone, pseudoecgonine methyl ester, apoatropin, hyoscyamine, tropacocaine, tiglypseudotropin, benzoylecgonine, homatropine, N,Ndibenzoylhydrazine, pristane and 8-azabicyclo $\{3,2,1\}$ octane3,6-diol,acetate(ester), tegafur and N-tris(hydroxylmethyl) methylglycine (tricine)), amides and amino acids compounds (d-tyrosine, tyrosine, N-tris(hydroxyl methyl) methyl glycine (tricine), benzonitrile,2-amino-, acryl amide (2-propenamide)), fatty acids and esters ( palmitic acid, heptanoic acid, ethyl ester (cognac oil), benzeneacetic acid,4-hydroxy-, methyl ester, 9,12-octadecadienoic $\operatorname{acid}(Z, Z)$ (linolic acid), 9,12-octadecadienoic acid (Z,Z)-,ethyl ester (linoleic acid ethyl ester), 9,12-octadecadienoic acid methyl ester(E,E), 9,12-octadecadienoic acid (Z,Z)-, methyl ester, oleic acid, glyoxylic acid, phenyl-ethyl ester, benzoyl formic acid (Phenyl glyoxylic acid), valeric acid, 2- hydroxyl- 4-,methyl methyl ester, plamitic acid, isovaleric acid, stearic acid,ethyl ester (octadecanoic acid ethyl ester), stearic acid (octadecanoic acid), glycerol,1-palmitate ethyl ester (hexadecanoic acid, ethyl ester), thiocyanic acid, phenyl methyl ester, benzoic acid,2chloroethyl ester, ketones compounds (ethanone,2-hydroxy1-phenyl (acetophenone,2-hydroxy-), isonitroso acetophenone (oximinoacetophenone). thiophene-3-carboxylate. terpenoids ( limonene oxide,trans) and phenol compounds (tyrosol (4-(2hydroxyethyl)phenol, 4-phenethylphenol, phenol,2-propyl-) and phenylglycol.

Chemical compounds of rats stomach contents treated with $40 \mathrm{mg} / \mathrm{kg}$ aqueous extract of leaves

The GC-MS analysis showed 15 compounds. These compounds are: Alkaloidial compounds (Scopolamine, Atropine, tropine, tropinone, 3-Tropanone, Pseudoecgonine methyl ester, Apoatropin, Hyoscyamine, Tropacocaine, Tiglypseudotropin, Benzoylecgonine, Homatropine and Tropic acid), Amino acids (Greatine(Glycine, N-(aminoiminomethyl)-N-methyl), fatty acids and esters (2-methylpyrazine-5-carboxylic acid, Azelaic acid, Oleic acid, Acetic acid, phenyl (Benzeneacetic acid), Valeric acid, 5-Aminovaleric acid, 3-methyl-, 3-Methyladipicacid, Butanoicacid,3-hydroxy-3-methyl-, Isovaleric acid,propylester, 9,12-Octadienoicacid(Z,Z), 9,12-Octadecadieneylchloride, (Z,Z), 5,6-dihydro-5methyluracil, 9,12-Octadecadienoicacid (Z,Z),methylester, n-Hexadecanoic acid (palmitic acid), d1-beta-phenyllatic acid (DL-alpha-Hydroxyhydrocininnamic acid), (Isovanillic acid), Hexanoic acid (13), Uric acid and VaniLlic acid), Terpenoidal compounds (Limonene oxide trans), ketone compounds (Gllacetophenone and Isocamphopinone) and hydrocarbon compounds (alkane (1-Fluorononane)).

Chemical compounds of rats stomach contents administered with $40 \mathrm{mg} / \mathrm{kg}$ aqueous extract of seeds

The GC-MS analysis revealed 18 compounds. These compounds are as follows: Alkaloidial compounds (Scopolamine, atropine, tropine, tropinone, 3-tropanone, pseudoecgonine methyl ester, apoatropin, hyoscyamine, tropacocaine, tiglypseudotropin, benzoylecgonine, homatropine, tropic acid), amides compounds (Greatine (Glycine,N-(aminoiminomethyl)-Nmethyl), fatty acids and esters (n-Butyric acid,2-ethylhexylester, Hexylisobutylcarbonate (carbonicacid) hexylisobutylester, Butanoic acid,octylester, 3-Hydroxy-4-methoxybenzoic acid (Isovanillic acid), Dehydroacetic acid, Uric acid, VaniLlic acid), ketone compounds (Gllacetophenone), Coummarin compounds (2,4-Dihydroxy-2,5-dimethyl-3(2H)-furan-3one, 4H-Pyran-4-one,2,3-dihydro-3,5-dihydroxy-6-methyl), Terpenoidal compounds (2-(hydroxymethyl)-2-nitro(glycerol), Limonene oxide trans) and Carbohydrates (Sucrose).

The new compounds detected in rats stomach contents treated with $40 \mathrm{mg} / \mathrm{kg}$ methanolic extracts of seeds and leaves

Compounds detected in the stomach content of treated rats and not detected in the control group and the crude extracts are as follows: treated with methanol extract of seeds are: Cyclohexane,1-methyl-2-pentyl, Phathalic acid, mono butyl ester, 2-n-Heptylfuran, Diamyl phthalate, 1,2-Benzenedicarbox lic acid, butyl 2-ethyl ester, 1,2-Benzene dicarboxylic acid, 2-ethoxy-2-ethylester, Diethyl phthalate and tropic acid while the treated with methanol extract of leaves are: (Tricine, Benzonitrile,2-amino-, Tyrosine, d-Tyrosine, Isonitrosoaceto phenone, Thiocyanic acid, phenyl methyl ester, Tegafur, Pristane, Glycerol,1-palmitate, N,N- Dibenzoylhydrazine, Tyrosol (4-(2-hydroxy ethyl) phenol, Benzoicacid,2-chloro ethyl ester, Phenol,2-propyl-, 4-Phenethylphenol, Phenylglycol, Benzeneacetic acid,4- hydroxy-,methyl ester, Propanoic acid,2-methyl-,2-ethyl-3-hydroxyhexyl, Benzeneacetic acid4hydroxy-, methyl ester, 3-Hexanol,3,5-dimethyl, Phenylethyl alcohol, Furan, tetrahydro-2-(methyoxymethyl), Plamitic acid, ethyl ester, Acrylamide, Heptane,2,5,5-trimethyl, Tetrahydrofurylacrylate, Valericacid,2-hydroxyl-4-,methyl methyl ester, Benzoyl formic acid, Glyoxylic acid, phenylethyl ester and Thiophene-3- carboxylate).

The new compounds detected in rats stomach contents after treatment with aqueous extracts of leaves and seeds

The new compounds detected in Stomach contents after administration with aqueous extracts of leaves and seeds are as follows: treated with aqueous extract of leaves are: 1,3-Dimethyl-3,4,56- tetrahyro-2(1H)-pyridinone, Isocamphopinone and Tropic acid while the treated with aqueous extract of seeds are: Tropic acid, and 1,3-Propanediol,2(hydroxymethyl)-2-nitro(glycerol).

\section{Discussion}

The seeds and leaves of Datura innoxia were widely used in west Sudan for traditional medicine. Most of the population does not know the toxicity and lethality of seeds and leaves. The chemical screening of Datura innoxia seeds and leaves (aqueous and methanol) extracts, revealed the presence of important pharmacological bioactive compounds mainly tropane alkaloids which are toxic at high concentrations, fatty acids, phenyls, phenyl propanoids, amino acids, 
amides, terpenoids, esters, ketones, coummarins, quinones and flavonoids. The aqueous (seeds and leaves) extracts, methanol (seeds and leaves) extracts have similar effect to the experimental rats, because they are all contain main alkaloidial compounds (atropine, hyoscyamine, tropacocaine, scopolamine, apoatropin) which have toxic effect.

\section{Conclusion}

The plant leaves and seeds contain elements of vital important for human metabolism. No toxic heavy metals was detected such as $\mathrm{As}, \mathrm{Sb}, \mathrm{Hg}, \mathrm{Cr}, \mathrm{Pb}$ and $\mathrm{Cd}$. The aqueous (seeds and leaves) extracts and methanol (seeds and leaves) extracts have similar effect to the experimental rats, because they are all contain main alkaloidial compounds (atropine, hyoscyamine, tropacocaine, scopolamine, apoatropin) which have toxic effect. The toxicity from oral administration of $40 \mathrm{mg} \backslash \mathrm{kg}$ daily of Datura innoxia seeds and leaves (methanol and aqueous) extracts for thirty days was less than the toxicity from oral administration of $60 \mathrm{mg} \backslash \mathrm{kg}$ and $80 \mathrm{mg} \backslash \mathrm{kg}$ of Datura innoxia seeds and leaves (methanol and aqueous) extracts, thus all rats which were oral administrated with the doses of $80 \mathrm{mg}$ $\mathrm{kg}$ daily were died within three weeks, main while the $75 \%$ of rats which were oral administrated with the doses of $60 \mathrm{mg}$ $\mathrm{kg}$ daily were died within thirty days. The lethal dose (LD50) of Datura innoxia seeds and leaves (methanol and aqueous) extracts in rats were nearly the same and parallel, that means they have the same efficacy due to their active ingredients (tropane alkaloids) this agree with the results of Mohammed A Abo Kutaifa et al., [12], in acute toxicity of aqueous and petroleum ether extracts of Datura innoxia leaves in mice. New compounds appeared in stomach contents in the treated groups and this suggest that some compounds were metabolized and circulated in the body after the oral administration of leaves and seeds extract.

\section{References}

1. UNESCO (1996). Culture and Health, Orientation Texts - World Decade for Cultural Development 1988 - 1997, Document CLT/DEC/PRO - 1996, Paris, France, 129.

2. Cowan MM (1999). Plants products as antimicrobial agents. Clinical Microbiology Reviews, 12(4), 564-582.

3. Nascimento GF, Juliana L, Paulo CF and Giuliana LS (2008). Antibacterial activity of plant extracts and phytochemicals on antibiotic-resistant bacteria. Brazilian Journal of Microbiology, 31(4), 247-256.

4. Latif A, Ahmad H, Begum S, Adnan M, Hassian S, and Waseem, M (2003). Medicinal and other economic plants as substitute to forest logging in Miandam and Sulatanr valleys, Swat. Proceedings of international lworkshop on conservation and sustainable use of medicinal and aromatic plants in Pakistan. WWF Pak., 101-105.

5. Preissel Ulrike and Hans-Georg Preissel (2002). Brugmansia and Datura: Angel's Trumpets and Thorn Apples. Buffalo, New York: Firefly Books, 106-129. ISBN 1-55209-598-3

6. Botswana Daily News No. 92. Tuesday May 19 (1998).
Poisonous sorghum meal: Consult nearest health facility.

7. Richard Evans Schultes (1970). The plant kingdom and hallucinogens (partIII), 25-53. https://catbull.com/alamut/ Bibliothek/The_plant_kingdom_and_hallucinogens part_III.pdf

8. Emboden W (2008). Narcotic Plants a lot of details about the history, chemistry and use of narcotic plants, including hallucinogens, stimulants, inebriants and hypnotics.

9. Sukhdev SH, Suman PSK, Gennaro L and Dev D R (2008). Extraction technologies for medicinal and aromatic plants. United Nation Industrial Development Organization and the International Center for Science and High Technology. https://www.researchgate.net/publication/285321042 Extraction_technologies_for_medicinal_and_aromatic_ plants

10. Organization for Economic Cooperation and Development (OECD 425), Guide lines for the testing Chemicals (2008) Acute Oral Toxicity: Up-and-Down procedure. https://doi. org/10.1787/9789264071049-en

11. Martin MH and Coughtrey PJ (1982). Biological monitoring of heavy metal pollution. Land and air. Applied Science, 475. https://www.cabdirect.org/cabdirect/ abstract/19851900604

12. Mohammed A Abo Kutaifa, DA Abbas and FM Kadhim (2012). Acute toxicity of aqueous and petroleum ether extracts of Datura innoxia leaves in mice. Al-Anbar Journal of Veterinary Sciences, 5(2), 68-74.
Copyright: (C2020 Ali A Eltayeib. This is an open-access article distributed under the terms of the Creative Commons Attribution License, which permits unrestricted use, distribution, and reproduction in any medium, provided the original author and source are credited. 